\title{
A Comparison of Different Models for Collection of WEEE in Europe
}

\author{
Marcos Dieste, Arcione Ferreira Viagi, Roberto Panizzolo, and Stefano Biazzo
}

\begin{abstract}
This work studies the two Reverse Logistics models used in European countries for collection of Waste of Electrical and Electronic Equipment (WEEE), compares their advantages and disadvantages and proposes a framework that helps the decision making process. The paper is articulated as follows. First, a literature review has been carried out regarding the two systems of WEEE Collection in the European Union: i.e. National Collective Scheme and Clearing House Model. Second, an integrated framework is proposed for managing Reverse Logistics in the disposal of electrical and electronic products and their components at the end of their lifetime. The proposed model may help in the decision making process of which collection system better fits the specific characteristics of a country.
\end{abstract}

Index Terms-Clearing house, European Union, national collective, recycling, reverse logistics, WEEE.

\section{INTRODUCTION}

In the last two decades, the problem related to pollution and environmental management, gained much importance. The concept of sustainable development, defined as development that "meets the needs of the present without compromising the ability of future generations to meet their own needs" [1] has become increasingly recurrent.

In this scenario, there is an increasing importance of the so-called reverse logistics understood as the collection of resources and activities dedicated to the recovery and recycling of end-of-life products discarded by users [2], [3]. These considerations are particularly important when referring to the production of electrical and electronic equipment (EEE), one of the fastest growing manufacturing sectors [4], in which technological innovation and market expansion continue to speed up the replacement process and the number of new applications of EEE.

In order to address environmental problems related to the management of WEEE, starting from the ' $80 / 90$ some EU Member States began to develop specific national legislations. Based on these considerations, the European Directive 2002/96/CE entered into force on January 272003 [5], [6]. This directive was aimed to prevent and limit the flow of waste electrical and electronic equipment (WEEE) and their components to landfill through reuse and recycling policies [7]. This Directive was revised with the publication of the Directive 2012/19/EU (entered into force on August 13, 2012) because of the increasing of this waste.

Manuscript received August 2, 2016; revised May 23, 2017.

The authors are with University of Padova, Italy (e-mail: marcos_dg@hotmail.com).
To appropriately manage the environmental problems associated with the recovery of WEEE in Europe, Directive 2012/19/EU imposes a separate collection of WEEE which must be guaranteed by appropriate systems so that users can easily discard their electrical and electronic equipments.

In this regard, the directive leaves to the producers the freedom to choose whether to fulfil their responsibility by implementing their own individual recovery system or participating in collective collection schemes or shared systems with other companies which are associated in order to reap the benefits of economies of scale. In the vast majority of European countries the most widespread collection system is of the second type.

Collective schemes can be divided into two main models [8]:

- National Collective Scheme;

- Clearing House Model.

Table I shows the current configuration and the actors in EU Member States and others, making evident a ratio of 2:1 in favour of the Clearing House model.

In the next section a description of the two types of collecting schemes is provided in order to understand how they work. The National Collective Scheme will be discussed first.

\section{NATIONAL COLLECTIVE SCHEME}

In a nation where it is implemented the National Collective Scheme model (NCS) may operate one or more schemes: in the latter case they are not competing with each other as they are responsible for the collection of different categories of WEEE. For example, in the Netherlands there are 2 national collective schemes. ICT Milieu is responsible for refuse collection of IT and Telecommunications products, while NVMP collects all other categories (WEEE is divided into ten categories: 1- Large household appliances, 2- Small household appliances, 3- IT and telecommunications equipment, 4- Consumer equipment, 5- Lighting equipment, 6- Electrical and electronic tools, 7- Toys, leisure and sports equipment, 8- Medical devices, 9- Monitoring and control instruments and 10- Automatic dispensers).

TABLE I: RECOVERY MODELS IN EU MEMBER STATES AND OTHERS

\begin{tabular}{cl}
\hline \hline \multicolumn{1}{c}{ Model } & \multicolumn{1}{c}{ Nation } \\
\hline \multirow{3}{*}{ Clearing House } & $\begin{array}{l}\text { Austria, Bulgaria, Croatia, Czech Republic, } \\
\text { Denmark, Finland, France, Germany, Ireland, Italy, } \\
\text { Latvia, Lithuania, Poland, Portugal, Romania, } \\
\text { Slovakia, Slovenia, Spain and United Kingdom. } \\
\text { Bational Collective } \\
\end{array} \quad \begin{array}{l}\text { Lelgium, Cyprus, Estonia, Greece, Hungary, } \\
\text { Sweden. }\end{array}$ \\
\hline \hline
\end{tabular}

Source: Authors 
Both schemes operate throughout the national territory. In this way they can manage the collection points in the best way to maximize efficiency logistics. Every scheme must report annually the environmental performance (defined as amount of WEEE collected and recycled percentage) to the Ministry of environment which in turn will report to the European Commission [9].

The systems are usually made by non-profit organizations or associations of producers in the sector. Each scheme is responsible for the collection, transportation and treatment of WEEE of producers or their affiliates. They run the system of collection, hiring logistics operators for transportation and recyclers for waste treatment.

In a national collective scheme it is still possible for a manufacturer decide to implement its own collection system. In that case, the producer must ensure that their products once discarded follow a return flow well configured and differentiated from the one used by the other producers: think for example the case of products which are collected into collection points set up by the manufacturer or by its dealers. If the product is discarded in common sites, where the WEEE is stored by category irrespective of brand, is the producer who decides to implement its own system of recovery and must ensure it can serve any public collection point. It is therefore necessary a very complex and extended recovery network; for this reason the majority of manufacturers, which has a return flow of their products well established and independent of that common, participates in collective schemes.

A brief explanation of the National Collective Model is shown in Fig. 1.

\section{Clearing House Model}

In the Clearing House model collective schemes operating in a nation are competing as they can treat the same categories of WEEE. Also in this case the schemes are responsible for the collection, transport and treatment of the products of affiliates and deal with logistics operators and recyclers in order to conduct these activities. This model is accompanied by a national registry with the following functions [9]:

- Define and manage allocation mechanisms of collection points to the various actors according to criteria of impartiality.

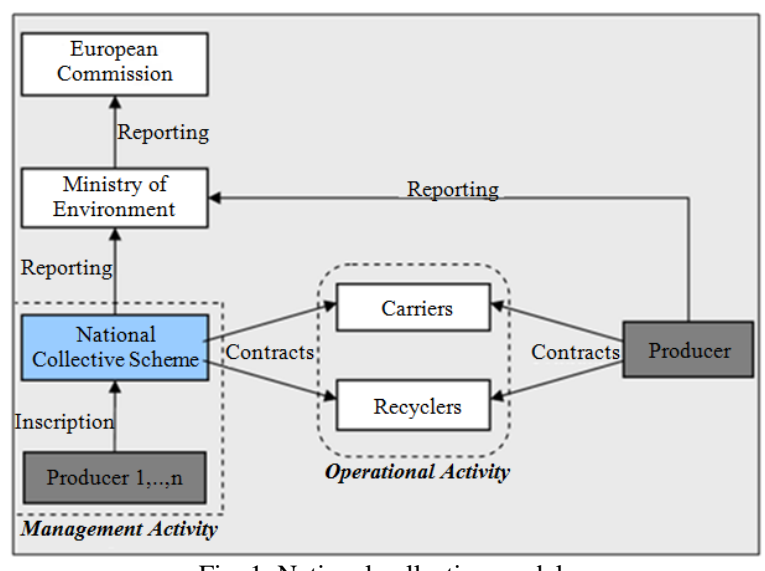

Fig. 1. National collective model.
This assignment must respect the collection scheme fee (defined on the basis of the market shares of the producers as it will be explained shortly) and must be impartial. The requirement of impartiality arises from the fact that not all areas have the same profitability. In fact, in urban areas is harvested much WEEE per unit area, unlike rural areas where picking up a small amount of waste over a large area make logistics costs much higher.

- Check that the systems fulfill their responsibilities and addressing the WEEE assigned.

- Report annually to the Ministry of the environment or the European Community environmental performance obtained.

If a manufacturer decides to implement its own system of recovery it must enrol in the national register and will be subject to the same allocation mechanism of collection points. Usually, producers are associated with one of the different schemes and are obliged to declare the kilograms of finished products (for each category) planning to sell in the domestic market during the current year. Then schemes provide data (grouped) to the national register which is now able to calculate the market share of each collective scheme by product category. The obligation of collection of WEEE must respect the market share of each system [10], [11].

It is important to underline that the amount of WEEE collected in the year may deviate significantly from quantities placed on the market by companies registered to them. The variance is mainly due to the presence of historical waste and orphan products. Historical waste is related to the fact that consumers still divest very old products (which have not been subjected to the directive). The amount of this refusal is decreasing over the years. The term orphan products refers to products that were manufactured by companies which are no longer available on the market, therefore, cannot fulfil their responsibility of producers by funding the operations of collection and processing.

For the moment, such a discrepancy between the amount of WEEE collected by schemes during the year and the quantity placed on the market by companies is handled without changing the proportion (in percentage terms) assigned to each individual forecast-based scheme. This means that the absolute amount collected varies.

We can see how the Clearing House Model operates in Fig. 2.

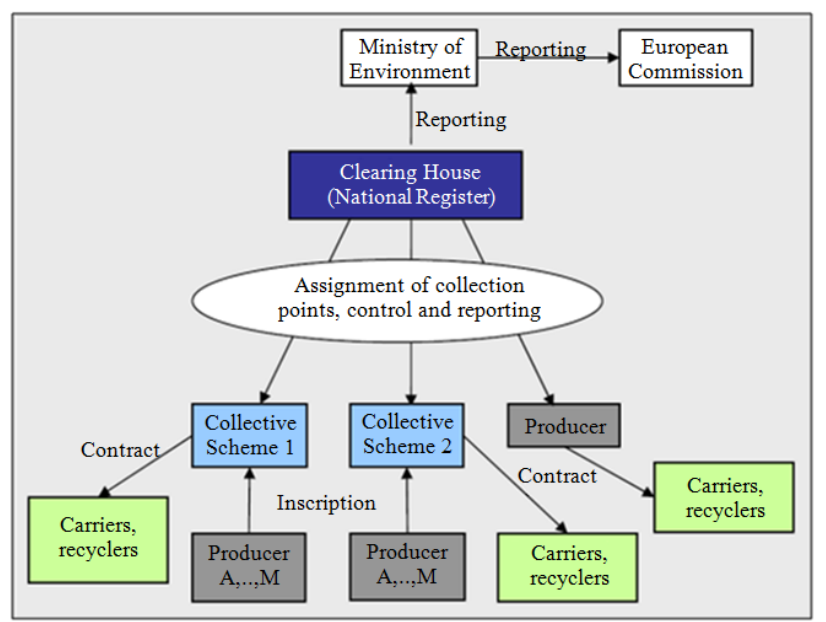

Fig. 2. Clearing house model. 
Under the Clearing House Model, the assignment of the collection points, by the national register, to the individual schemes can be (a) periodical or (b) immediate.

\section{A. Periodical Assignment (a)}

In periodical assignment there are two different ways of dividing the territory called respectively by zone and by site.

With periodic assignment by zone (a1) the country is divided into areas (regions, provinces, etc.) and all the collection points of each zone are assigned to the different collective systems over a period of time (typically one year). In order to give each scheme a collective amount of waste that reflects the predetermined market share, is needed a prediction of how much WEEE will be collected at each collection point and therefore in each area. The allocation of collection points for a given period arises a problem related to fairness among the schemes which compete in collecting waste. A scheme collecting WEEE in urban areas will be in advantage compared to a scheme that collects waste in rural areas as the costs for their recovery and their treatment will be lower at equal quantity collected.

In the case of periodic assignment by site (a2) the single collection points are allocated to the various collecting schemes irrespective of the geographical area to which they belong. In order to proceed to the periodic assignment, it is necessary to forecast the amount of waste that will be collected in each collection point, while is no longer needed the division of zones with the same profit. It is desirable however, certain uniformity in the assignment of collection points distinguishing between urban and rural areas to provide a degree of equity between schemes. Therefore, a fundamental problem in periodic assignment is to respect the market share of the schemes. To have a certain level of efficiency in this regard, the predictions about the waste that will be collected must be accurate enough.

\section{B. Immediate Assignment by Site (b)}

In this case the assignment does not take place periodically, in accord to a specific timeframe, but it is immediate. When the single collection point is full, it is required the intervention of a collecting scheme to gather the waste. It is the national register that chooses the collecting scheme which at that time has the lowest collection rate.

TABLE II: WEEE COLLECTION SYSTEMS CLASSIFICATION SCHEME

\begin{tabular}{ccc}
\hline \hline Model & $\begin{array}{c}\text { Assignment of } \\
\text { collection points }\end{array}$ & Land subdivision \\
\hline National Collective & Absent or by category & $\begin{array}{c}\text { Unified management of } \\
\text { the nation }\end{array}$ \\
\hline \multirow{2}{*}{ Clearing House } & Periodic (A) & By zone (a1) \\
\cline { 2 - 3 } & Immediate (B) & By site (a2) \\
\hline \hline Source Authors
\end{tabular}

Source: Authors

It is of primary importance for proceeding with the assignment of the collection points that the national register knows in real-time the amount of waste collected until that time by each collective scheme. In this sense, it is required the presence of a national coordinating body recognized by all players in the game.

The observations made so far concerning the two schemes in Europe for the collection of WEEE are summarized in
Table II. Take into consideration that in the case of National Scheme model the assignment of collection points is absent or is made by category. This means that in a given geographical area there is:

- only one operator who collects all categories of WEEE;

- two or more operators who are not in competition because each of them collects only a specific category of WEEE.

\section{A CRITICAL ANALYSIS OF THE EUROPEAN WEEE COLLECTION SYSTEMS}

This section of the paper presents a critical analysis of the two main models employed in the European Union for collecting and recycling WEEE. The analysis will highlight advantages and disadvantages of each system especially regarding the economic and logistical performance.

\section{A. Comparison between the National Collective Scheme and the Clearing House Model}

Let us now turn our attention to the comparison between the Clearing House Model and National Collective Scheme. It is worth noting that the ability to assess and compare in detail the two types of systems depends on the quantity and quality of available data, in particular as regards the Clearing House system which is a more recently implemented model. Moreover, the Clearing House system is a highly competitive model, therefore players are reluctant to reveal data about costs and prices charged to producers.

The comparative analysis will be conducted by examining the items showed in Table III.

TABLE III: MAIN VARIABLES USED TO COMPARE DIFFERENT COLLECTING MODELS

\begin{tabular}{lcc}
\hline \hline \multicolumn{1}{c}{ Variables } & $\begin{array}{c}\text { National } \\
\text { Collective }\end{array}$ & $\begin{array}{c}\text { Clearing } \\
\text { House }\end{array}$ \\
\hline 1 - Logistics efficiency & High & Low \\
2 - Level of complexity & Low & High \\
3 - Impartiality & Absent & Present \\
4 - Level of Competition between schemes & Absent & High \\
5 - Overall effectiveness of the collecting system & High & Low \\
6 - Overall efficiency of the collecting system & & \\
6.1 - Economies of Scale & Yes & No \\
6.2 - Small size of the nation's population & Appropriate & Not \\
6.3 - Producers with well-established and & Appropriate & Not \\
independent return flow for each product & appropriate \\
\hline \hline Source: Authors
\end{tabular}
Source: Authors

\section{1) Logistics efficiency}

The logistics efficiency is certainly higher in National Collective model, where the scheme is responsible of the collection of all WEEE or certain categories of them, throughout the national territory. National collective scheme can be assigned to various service providers (i.e. transporters and recyclers), zones or collection points by researching the logistics efficiency and thereby minimizing the total costs in the absence of particular constraints [12]-[14]. We have to note that periodic assignment in the Clearing House Model can achieve logistics efficiency, which derives from the benefits of routine and data sharing, this is explained in more detail in section IV.B.

2) Level of complexity 
The literature review demonstrates that an implementation of National Collective is easier than build up a Clearing House Model. There is no doubt that the Clearing House model would prove to be more complex than the National Collective scheme because of the number of actors involved in recovery and treatment of WEEE. It also needs the presence of the national registry and the implementation of a model for the allocation of points of collection. This situation creates a duplication of infrastructure and roles, and then, ultimately, the emergence of additional costs for coordination activities [12], [14], [15].

\section{3) Impartiality}

An impartiality between schemes results ultimately in a neutrality between producers. In National Collective Scheme the issue of impartiality between schemes does not arise as shown before. In the Clearing House Model instead, this problem can arise if it is not properly handled [12], [14].

\section{4) Level of competition between schemes}

Clearing House system is characterized by being a very competitive model: the producers may choose to subscribe to the scheme that offers them the lower price for product recovery. This makes the business environment more nervous and brings every single scheme to a continuous research of optimization of production factors involved [16], [17]-[19]. This high level of rivalry is not present in the National Collective Model. The presence of many companies competing with each other (as it happens in the Clearing House Model) leads to a higher overall efficiency and therefore to a reduction of costs for the collection and disposal of WEEE. This consideration is supported by the analysis of the financial statements of collecting firms: in many cases National Schemes have higher levels of expenditure compared to the Clearing House model. The analysis of efficiency level of the two models will be detailed shortly.

\section{5) Overall effectiveness of the collecting system}

Another interesting element of comparison of the two systems relates to the effectiveness of the collection in terms of the amount of waste recycled over the total of waste discarded annually. The analysis of available data shows that National Collective schemes tend to exceed by far the objectives laid down by the community legislations, supporting an "environmental tension" based on a strong ethos of recycling and investing more on information to citizens in order to generate change in behaviour. Figure 3 shows the number of kilograms of WEEE collected per person in some European countries. Note that the national collective systems of Norway, Sweden and Belgium exceed by far the target set by the Community directive of 4 $\mathrm{kg} / \mathrm{capita}$ being much more effective than those applying Clearing House [14].

\section{6) Overall efficiency of the collecting system}

The analysis of the overall efficiency of a collection system is done by studying the following points.

\section{a) Economies of scale}

The collection and processing of waste need substantial infrastructure investments. To achieve a considerable reduction in costs, it is therefore crucial to collect and process large quantities of waste. From this point of view, the National Collective Scheme is better than the Clearing House Model. Indeed, in this latest model, there are many schemes which are competing for the WEEE to be collected in proportion to their market share. When there are a large number of collection schemes the market share of the collecting companies decrease. So it is better to apply a National Collective Model [12], [14], [15].

b) Small size of the nation's population

A second variable that may influence the overall efficiency of the system is the size of the country. The Clearing House system is not appropriate in small nations where the amount of WEEE to retrieve probably does not justify the additional costs of the proliferation of infrastructures and the duplication of functions, developing logistics costs and extra management due to the mechanism of allocation of collection points and the fragmented management of the territory. Therefore, in the small or lightly populated nations is better to apply a National Collective Model. Conversely, in large countries such as Germany and France, the disadvantages associated with the model Clearing House could be offset by benefits from larger amounts that are collected and with a strong competition between schemes; benefits in small states do not seem to be sufficient to support multiple schemes together in competition [14], [15].

c) Producers with well-established and independent return flow for each product

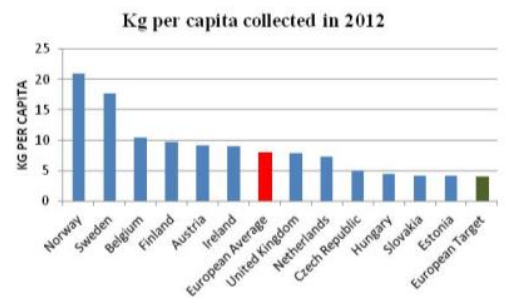

Fig. 3. WEEE collected in 2012 (kg per capita) [20].

When the producers have a return flow for each category of WEEE the National Collective model is better than the Clearing House model because every product will be collected by a single firm [14].

\section{B. Comparison between Periodical and Immediate Assignment}

As described previously (see Table II), in the Clearing House model there are two different ways for the assignment of collection point to the scheme namely Periodical Assignment and Immediate Assignment. We can now make a comparative analysis of these two methods in terms of:

- Logistics efficiency: total cost necessary to support collection and disposal activities;

- Degree of impartiality: ability of the system to ensure fair assignment of WEEE volumes between the various competing schemes;

- System complexity related to the amount of data to be produced and shared among the various actors.

Periodic Assignment presents a logistical efficiency greater than the Immediate Assignment. The first, makes possible to strengthen relationships between carriers and collection points, obtaining benefits from routine and 
optimization because are known in advance the points to serve even if it is not known the time of collection. The ability to schedule the travel through the collection points and to define some "efficient" paths is even stronger when the regular assignment is accompanied by a division of the territory in zones (Periodical Assignment by zone) being able to leverage greater closeness of collection points. On the contrary, Immediate Assignment produces a situation in which none of the schemes can know in advance the place and the time of collection. This makes hard the consolidation of relations between the carriers and the points of collection and the possibility to operate with full load carriers.

As regards impartiality between the schemes, Immediate Assignment seems better than Periodical Assignment making sure that (as we discussed in the previous paragraph) at any given moment all the schemes have taken up the same percentage of WEEE in relation to their share of the market. Periodical Assignment needs to forecast the WEEE that will be collected. The process of elaborating these forecasts is complex because requires a database of historical amount of waste collected and of the products placed on the market in the year.

\begin{tabular}{|c|c|c|c|}
\hline \multirow{2}{*}{ Logistics Efficiency } & B & $\mathrm{a} 2$ & a1 \\
\hline & - & & -1 \\
\hline \multirow{2}{*}{$\begin{array}{c}\text { Degree of } \\
\text { impartiality }\end{array}$} & $\mathrm{a} 1,2$ & & B \\
\hline & al 2 & & $T$ \\
\hline \multirow{3}{*}{$\begin{array}{c}\text { System } \\
\text { Complexity }\end{array}$} & 1 & & 1 \\
\hline & & & \\
\hline & Low & & High \\
\hline
\end{tabular}

Fig. 4. Qualitative comparison between the various configurations of the clearing house model.

As seen above, the historical WEEE is still a significant fraction of what is collected; there may be a substantial deviation between products that are placed on the market and waste that is collected.

Therefore, the prediction of WEEE collected at various points will be an approximation of what they actually contribute to the return flow. At the end of the period (typically a year) it could happen that one collective scheme have collected more waste than those that were assigned based on its market share. In this case, the national registry will have to make corrections for the next year and this may cause an increase in costs, and will be compensated with the rise of prizes. This phenomenon could lead to an extreme situation where the collective scheme loses part of its members in favour of cheaper schemes.

The last aspect we analyse is the general complexity of the system. For a proper performance of the Immediate Assignment method, it is imperative that the national register knows in real time the WEEE collected by each of the schemes. This means that it is needed the implementation of an efficient information system extended to the whole chain of recovery with strong involvement of all the stakeholders. This database requires constant and accurate updating of the data. In the case of periodic assignment is not necessary an information system so complex but it is important to have a high amount of data regarding waste collected in the preceding period in order to formulate more accurate forecasts.

These considerations made so far about the Clearing
House Model are summarized in Fig. 4.

\section{Conclusions}

In this paper we have first identified two types of collective schemes used in the European countries for the recycling of WEEE: namely National Collective Scheme and Clearing House Model. Considering the current situation in Europe, there is a ratio of 2:1 in favour of the Clearing House model.

Secondly, we have conducted a comparative analysis of these two systems highlighting their advantages and disadvantages. In order to carry out this analysis we have identified some variables which are represented in Table III. We think that this framework is useful for comparing different collecting systems.

Given the more complexity of the Clearing House model, we have also developed a second framework for a better comparison between the two assignment procedures which can be found in this model (see Fig. 4).

These two frameworks could help in the decision making process of the model which better fits the specific characteristics of a country. It is evident that in each single situation the decision-maker should identify which variables are more relevant than the others, in other words this means that a specific weight must be assign to each variable.

The proposed framework has been elaborated from a literature review of pertinent studies: the variables included are those which have a major relevance in the decision making process.

However, there are other contingent factors that should be taken into consideration for choosing an appropriate collecting system. These elements refer to the so called "environmental factors". For example, [15] in a recent study points out that the culture of recycling in a country and the ecological awareness of citizens are important factors in assessing the amount of WEEE collected in absolute terms and per capita. Other factors cited in the literature are:

- impact of extension, geography and orography of the collection area on collection and transport logistics costs [21];

- population size and density. Countries with large populations and/or large urban areas can generate greater efficiency in harvesting operations;

- categories of waste treated;

- large volumes of WEEE can achieve economies of scale and greater efficiencies through better rationalization of infrastructure and contracts with service providers [22], [23];

- country's economic development level: the more is the economic development, the greater is the volume of WEEE to dispose of;

- labour cost. The collection, division and treatment of WEEE are labour-intensive operations: availability in terms of quality and quantity and flexibility of productive factors and their costs play a relevant role on the efficiency and effectiveness of the recovery system;

- economies of experience;

- suppliers availability. The ability to work with multiple service providers (typically transporters and recyclers) 
enables competition and this leads to higher operational flexibility and avoids the risk of "opportunistic conduct":

- levels of safety and quality control standards. WEEE recycling require appropriate safety levels and quality controls which may vary from country to country. It is obvious that a higher level of standards may result in higher costs. The use of more advanced technologies for WEEE treatment will make recycling more efficient in the future; for some categories of waste it will generate revenues that cover the related costs [8].

\section{REFERENCES}

[1] WCED (World Commission on Environment and Development), Our Common Future, Oxford, Oxford University Press, 1987.

[2] S. Jofre and T. Morioka, "Waste management of electric and Electronic equipment: Comparative analysis of end-of-life strategies," Journal of Mater Cycles Waste Manag, vol. 7, pp. 24-32, 2005.

[3] R. F. Santos, "Proposta de um modelo de gestão integrada da Cadeia de suprimentos: Aplicação no segmento de eletrodomésticos," Doctoral dissertation, Tese de Doutorado-Instituto Tecnológico de Aeronáutica, São José dos Campos, 2010.

[4] R. Hischier et al., "Does WEEE recycling make sense from an environmental perspective? The environmental impacts of the Swiss take-back and recycling systems for waste electric and electronic equipment (WEEE)," Environmental Impact Assessment Review, vol. 25, pp. 525-539, 2005.

[5] BIS (Bio Intelligence Service), "Gather, process, and summarise information for the review of the waste electric and electronic equipment directive (2002/96/EC), ENV.G.1/FRA/2004/0081, study no. 16," Synthesis Report, 2006.

[6] Perchards, "Transposition of the WEEE and RoHS directives in other EU member states, By Perchards for DTI, United Kingdom," 2005.

[7] Stephan Schmidheiny and BCSD (Business Council for Sustainable Development), "Changing course a global business perspective on development and the environment," Cambridge, MIT Press, 1992.

[8] M. Savane et al., "Implementation of the waste electric and electronic equipment directive in the EU, Institute for Prospective Technological Studies (IPTS)," European Commission, 2006.

[9] EU Directive 2002/96/CE of the European Parliament and of the European Council of 27 January 2003 on waste electrical and electronic equipment (WEEE), EU Official Journal, February 13 , 2003.

[10] C. George et al., "The producer responsibility principle of the WEEE directive," Final Report, DG ENV, 2007.

[11] J. Huisman et al., "2008 review of directive 2002/96 on waste electrical and electronic equipment (WEEE)," Final Report, United Nations University, 2007.

[12] Holland. (2011). The Dutch WEEE Flows. [Online]. Available: http://ec.europa.eu/environment/waste/weee/pdf/Report_Dutch_WEE E_Flows\%202012\%2003\%2015.pdf. Accessed 10/04/2016

[13] Sweden. (2009). WEEE Directive in Sweden - Evaluation with future study. [Online]. Available: http://www.swedishepa.se/Documents/publikationer/978-91-620-842 1-9.pdf, accessed 30/05/2016

[14] J. Ylä-Mella et al., "Overview of the WEEE directive and its implementation in the Nordic countries: National realisations and best practices," Journal of Waste Management, 2014.

[15] FES - Future Energy Solutions, "Study into European WEEE schemes," Report to U.K. Department of Trade and Industry, 2003.

[16] Denmark. (2005). The environmental protection Act: Producer responsibility for electronic waste. Act no. 385 of 25 May 2005 [Online].

Available: https://www.dpa-system.dk/en/WEEE/ProducerResponsibility/Legisla tioninDenmark. Accessed 20/05/2016

[17] ECODOM, Household WEE generated in Italy, 2012.

[18] Germany. (2005). Act governing the sale, return and environmentally sound disposal of electrical and electronic equipment. [Online] Available: http://www.pro-e.org/files/elektro_g_e.pdf

Spain. (2015). Spanish legislation on waste of electric and electronic equipments (WEEE). [Online]. Available: http://www.magrama.gob.es/es/calidad-y-evaluacion-ambiental/temas/ prevencion-y-gestion-residuos/flujos/domesticos/fracciones/aparatos electr/Royal-Decree-on-wastes-electronic-electric-equipments.aspx

[19] EUROSTAT. (2015). Waste statistics-electrical and electronic equipment. [Online]. Available: http://ec.europa.eu/eurostat/statistics-explained/index.php/Waste_stati stics_-_electrical_and_electronic_equipment

[20] ADEME, "Etude des coûts de collecte primaire des DEEE supportés par les collectivités locales," Rapport Final, France, 2006,

[21] ACRR-The Association of Cities and Regions for Recycling, "Management of waste electrical \& electronic equipment - A guide for local and regional authorities, "Brussels, 2003.

[22] M. Walls et al., "Private markets, contracts and government provision: What explains the organization of local waste RECYCLING markets," Urban Affaire Review, vol. 40, no. 5, pp. 337-361, 2005.

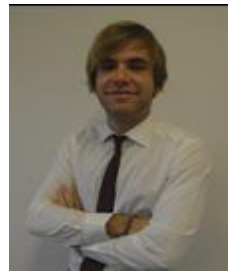

Marcos Dieste holds an MSc in management engineering from the University of Zaragoza, Spain. In 2014, he got his degree in business administration and management at the same university. He is at this time studying the $\mathrm{PhD}$ program in management engineering at the University of Padova, Italy.

After some years working in industrial, consultancy and managerial ambients he is currently researching in the industrial operations, sustainability and service management fields at the Department of Management Engineering of the University of Padova.

Arcione Ferreira Viagi holds a post-doctorate in management engineering at the University of Padova, Italy in 2015-2016, PhD in aeronautical and mechanics engineering at the Technological Institute of Aeronautics - ITA, Brazil in 2011, the master in communication and market at the Faculdade Cásper Líbero, Brazil in 2001, specialization in production administration and industrial operations at Fundação Getulio Vargas, Brazil in 1999 specialization in financial administration at the University of Taubaté. Brazi in 1986, mechanical engineering at the University of Taubaté, Brazil in 1985.

$\mathrm{He}$ has 24 years' experience as an executive in Brazilian and multinational companies, initially acting as an executive in the area of production management and reaching the general management of business unit in the area of pulp and paper and steel. He is a visiting professor in post-graduate courses of the Faculty Trevisan, Universidade Federal Fluminense, Instituto Nacional dePós-graduação, Universidade de Vale do Paraíba, Faculdade de Diadema, Instituto de Ensino de Londrina and Instituto de Pós-graduação, teaching Production Management, Supply Chain Management, Industrial Logistics, Lean Manufacturing, Industrial Marketing, Product Development and Market, Strategic Planning, Market Planning, Economic Engineering and Decision Making under Uncertainty.

Viagi has publications in several areas of knowledge due to extensive and general training and experience.

Roberto Panizzolo holds an MSc in electronic engineering and a $\mathrm{PhD}$ in industrial engineering from the University of Padova, Italy. He is currently associate professor of operations and supply chain management at the Department of Management and Engineering (DTG), University of Padova. $\mathrm{He}$ has worked on many national and EU projects and his research has appeared in a number of books and international journals. He is a member of the European Operations Management Association and of the Production and Operations Management Society.

Prof. Panizzolo has more than 20 years of experience in the field of Operations Management and he is a senior consultant and qualified teacher and instructor for business organizations $\mathrm{He}$ is the director of the post-graduate course in Lean Manufacturing of the School of Engineering, University of Padova.

Stefano Biazzo holds an MSc in electronic engineering, an MBA and a PhD in management from the University of Padova, Italy. He is currently associate professor of innovation management at the Department of Management and Engineering (DTG), University of Padova.

On issues of product innovation and organizational innovation he has published in international journals and his research has also appeared in a national and international books. His commitment as a trainer, consultant and researcher is driven by a passion for the development and dissemination of ideas, methodologies and tools to enhance the innovative capacity of firms. $\mathrm{He}$ is the director of the post-graduate course in Lean Office \& Service of the School of Engineering, University of Padova. 